It is here that the radio transmitters come in. Because of the fact that the technique of VLBI measures the rotation of the group of transmitters about the line of centres of the Earth and the Moon, it is insensitive to the Earth's rotation and to the Moon's orbital motion, and so leads to a very clear separation of the librations from other motions. The publication (King et al., op. cit.) of the results obtained by combining lunar laser ranging with VLBI observations of the lunar radio transmitters is thus a landmark in lunar studies. The remarkably low uncertainty of 0.003 is attributed to the estimate of 0.392 for the value of the non-dimensional polar moment of inertia. It is aiso important that certain of the higher gravitational harmonics can be derived from the librations because there are considerable uncertainties in their derivation from the orbits of artificial satellites alone.

Clearly a great advance has been made in our knowledge of lunar dynamics in the past few years, and that in itself emphasises how much there is still to learn about the dynamics of the Earth. As already mentioned, one of the most important steps forward would be to obtain data from a lunar laser ranging observatory in the Southern Hemisphere, and there are indeed now good prospects of obtaining such data as a result of cooperation between US and Australian groups, in which British workers are also participating. As ever when new possibilities of precise measurements are realised, a new world of knowledge seems to be opening.

\section{Cheap uranium from bacteria?}

\section{from a Correspondent}

An International Atomic Energy Agency research coordination meet ing on the bacterial leaching of uranium ores was held at the University of Warwick on December 13-15, 1976 under the chairmanship of Professor Donovan Kelly, of the Department of Environmental Sciences, University of Warwick. The meeting was formally hosted by the UK Department of Energy.

DURING the 1960s it was found that uranium could be recovered from the acidic waters running through dumps of uranium mining wastes or from water hosed on to the walls of workedout uranium mines. This solubilisation of uranium was subsequently found to be due to the activity of a specialised group of unusual bacteria called Thiobacillus ferrooxidans, which obtain energy for their growth from oxidising iron from the ferrous to ferric form in very acidic environments. These bacteria are always found in acid mine waters when pyrite (iron sulphide) is present in the ore being mined. They attack the pyrite and produce sulphuric acid and ferric iron, which in turn chemically converts the insoluble uranium ore into soluble uranyl sulphate. The possible economic importance of this process as a potentially cheap means of uranium recovery was early recognised by the IAEA, whose headquarters are in Vienna, and which has supported research and development into the bacterial leaching of uranium for a number of years.

The meeting at Warwick University was the third coordination meeting (earlier ones were in Ankara in 1972 and Vienna in 1974), held to review recent developments and to review the present status of the whole subject after some ten years of active work in many countries. Scientists from Austria, Canada, Finland, Hungary, India, Romania, South Korea, Yugoslavia and the UK and USA took part. Much of the work discussed had been financed by the IAEA and ranged from the basic microbiology of the process over economic aspects to the safety and control of uranium recovery.

With the likely demand for uranium for nuclear power generation in the Western World alone between 19762000 standing at 4 million tonnes of $\mathrm{U}_{3} \mathrm{O}_{8}$, mining companies have increasingly been looking at ways of recovering uranium from ores containing progressively less uranium, and to ways of recovering the small amounts of uranium left in the wastes from the processing of richer ores. Bacterial leaching provides just such a process, since the bacterial activity is as effective in removing essentially all the uranium from a $0.03 \% \mathrm{U}_{3} \mathrm{O}_{k}$ ore as from a $0.3 \%$ ore, without necessarily being more costly, whereas the difference between these ores for conventicnal extraction processes is sufficient for the lower grade one to be uneconomic to work at acceptable prices. Bacterial leaching thus enables countries with only low-grade 'uneconomic' ores to exploit their natural resources cheaply and of course can also be used for low cost recovery of uranium from high-grade ores.

Since the IAEA programme began. the state of the art of bacterial leaching has progressed from minimal understanding and exploitation to the current state of having a rather full understanding of the fundamental microbiology and biochemistry of the process, to have proved large scale pilot plants and built at least one commercial scale plant. The latter, reported at the meeting, will become operational in Canada in 1977 and will produce a million pounds of $\mathrm{U}_{3} \mathrm{O}_{8}$ a year, using 3,000 tonnes of crushed ore per day.

The meeting discussed the basic studies of growth and physiology of the iron bacteria, largely carried out by Professor Kelly's group, the immunological characterisation studies performed in Korea, and work on the control of leaching activity and pilot plant operation in Romania, Yugoslavia and India. Much time was devoted to the evaluation of large scale plants, their engineering design, efficiency, responses to environmental factors such as seasonal temperature variation, supply of oxygen and of other nutrients, and possible hazards in the operation of the extraction systems. Britain has been active in the design and evaluation of practical leaching systems and the use of the bacteria to generate ferric iron from various sources to be used in leaching. A report on the work of the Warren Spring Laboratory in this field was received with considerable interest. The very large scale alkaline leaching of uranium in Hungary was reported in full and provided further information of basic use in plant design.

The conclusions of the meeting, reported to the IAEA, included the recommendation that bacterial leaching of uranium should be developed and encouraged as a cost-competitive method of recovering uranium, involving smaller capital and running costs than conventional methods, with the incalculably valuable bonus of enabling treatment of ores otherwise prohibitively costly to treat. It was foreseen that work in this field would proceed to progressively more controlled processes and that the areas requiring further work could be detected by constructing the realistic process flow sheets and mathematical models that work to date had made feasible.

A long-standing problem in many mining operations is the release of polluting acids and metals into the environment. One conclusion of this meeting was that controlled exploitation of leaching of waste rock from conventional mining operations was to be encouraged and exploited not only to recover uranium and other metals, but to minimise the likelihood of environmental pollution by uncontrolled natural leaching. It is clear that the economic, biological, sociological and engineering aspects of the bacterial recovery of uranium will occupy many workers for years to come. 